\title{
ORIGINAL
}

\section{Hyperbolic correlation between insulin sensitivity and insulin secretion fades away in lean subjects with superb glucose regulation}

\author{
Toru Aizawa ${ }^{1)}$, Masayuki Yamada ${ }^{2)}$, Masafumi Katakura ${ }^{3)}$, Yoshiko Funase ${ }^{1)}$, Koh Yamashita ${ }^{1)}$ and \\ Keishi Yamauchi $^{1)}$ \\ 1) Diabetes Center, Aizawa Hospital, Matsumoto, Japan \\ ${ }^{2)}$ Clinical Biometrics, Planning and Managing Department, Kissei Pharmaceutical Co., Ltd., Tokyo, Japan \\ ${ }^{3)}$ Department of Medicine, Chikuma Central Hospital, Chikuma, Japan
}

\begin{abstract}
The relationship between insulin sensitivity ( $\mathrm{Si}$ ) and insulin secretion $(\beta)$ was analyzed in 533 health examinees. The subjects underwent a $75 \mathrm{~g}$ oral glucose tolerance test, with plasma glucose (PG) and immunoreactive insulin (IRI) determined at fasting, $30 \mathrm{~min}$ and $120 \mathrm{~min}$, and were classified according to the current criteria as normal glucose tolerance (NGT, n=328), non-diabetic hyperglycemia $(\mathrm{NDH}, \mathrm{n}=113$ ) including impaired fasting glucose and impaired glucose tolerance, and diabetes mellitus (DM, $\mathrm{n}=72$ ). NGT was subdivided by fasting PG (FPG) tertile, $\leq 4.9,5.0-5.4$ and 5.5-6.0 $\mathrm{mM}$, into $\mathrm{NGT}_{\mathrm{FPG} 1}, \mathrm{NGT}_{\mathrm{FPG} 2}$ and $\mathrm{NGT}_{\mathrm{FPG} 3}$, or by body mass index (BMI) tertile, $\leq 21.8,21.9-24.4$ and $\geq 24.5 \mathrm{~kg} / \mathrm{m}^{2}$, into $\mathrm{NGT}_{\mathrm{BMI} 1}, \mathrm{NGT}_{\mathrm{BMI} 2}$ and $\mathrm{NGT}_{\mathrm{BMI} 3}$. As an index of $\mathrm{Si}$ and $\beta$, Matsuda index=10,000/sqrt [FPG.FIRI·2hPG.2hIRI] and $\delta \mathrm{IRI}_{0-30} / \delta \mathrm{PG}_{0-30}$, were employed respectively: FIRI, $2 \mathrm{hPG}$ and $2 \mathrm{hIRI}$ denote fasting IRI, $2 \mathrm{~h}$-post glucose PG and IRI, respectively. Correlation between $\mathrm{Si}$ and $\beta$ was evaluated by Spearman's rank correlation and the parameters for $[\beta]=a \cdot[\mathrm{Si}]^{b}$ were obtained by standardized major axis (SMA) regression. Si- $\beta$ correlation was strongest in NDH (Spearman's rho=0.546 , SMA regression $\left.r^{2}=0.277\right)$, intermediate in DM $\left(r h o=-0.432, r^{2}=0.193\right)$ and weakest in NGT $\left(\mathrm{rho}=-0.201, r^{2}=0.039\right)$. Spearman's rho for the Si- $\beta$ correlation was significantly lower in NGT than in NDH $(p=0.003)$. Si- $\beta$ correlation was significant in $\mathrm{NGT}_{\mathrm{FPG} 3}, \mathrm{NGT}_{\mathrm{FPG} 2}$ and $\mathrm{NGT}_{\mathrm{BMI}}$, but not in $\mathrm{NGT}_{\mathrm{FPG} 1}, \mathrm{NGT}_{\mathrm{BMI} 2}$ and $\mathrm{NGT}_{\mathrm{BMI} 1}$. The slope, $b$, was -1.184 1.530 without significant differences between any groups. In conclusion, the hyperbolic Si- $\beta$ correlation was weaker in NGT than in NDH and absent in NGT subjects belonging to the lowest FPG or BMI tertile.
\end{abstract}

Key words: Beta cell function, Insulin sensitivity, Hyperbolic law, Glucose tolerance

PLASMA GLUCOSE (PG) level is maintained within the normal or near normal range even if insulin sensitivity (Si) is diminished. A typical example is obesity. In many obese subjects, normoglycemia is maintained despite low Si. In this situation, insulin secretion $(\beta)$ usually increases. The opposite holds true for athletes who are euglycemic with increased Si and lowered $\beta$. Accordingly, in apparently healthy population, there is an inverse correlation between $\mathrm{Si}$ and $\beta$, which is expressed as $[\beta]=a \cdot[\mathrm{Si}]^{b}$ with the exponent $b$ being not significantly different from -1 [1-4].

However, we consider that the characteristics of the

Submitted Jul. 26, 2011; Accepted Nov. 2, 2011 as EJ11-0162 Released online in J-STAGE as advance publication Nov. 18, 2011

Correspondence to: Toru Aizawa, Senior Consultant, Diabetes Center, Aizawa Hospital, 2-5-1 Honjo, Matsumoto 390-8510, Japan.

E-mail: taizawax@ai-hosp.or.jp
Si- $\beta$ correlation in the general population have not yet been fully elucidated. The heterogeneity of normal subjects with respect to the relationship between insulin secretion and insulin sensitivity, i.e., poor inverse correlation between fasting plasma insulin concentration and $\mathrm{Si}$, was briefly described in the original study [1]. More recently, we [5] and others [6-8] have definitively established the heterogeneity of insulin-glucose interplay in subjects with normal fasting glucose (NFG) or normal glucose tolerance (NGT). Nevertheless, the relationship between $\mathrm{Si}$ and $\beta$ in apparently healthy subjects has been studied by treating NGT as a single population, and the general consensus is that there is a progressive left and downward shifting of the regression curve, $[\beta]=a \cdot[\mathrm{Si}]^{b}$, with worsening of glucose tolerance [9-18]. In some studies, non-hyperbolic regression of $\mathrm{Si}$ to $\beta$ was reported $[4,15,16]$. 
We hypothesized that the hyperbolic regression between $\mathrm{Si}-\beta$ is not a priori, and therefore systematically analyzed data from apparently healthy subjects containing NGT, non-diabetic hyperglycemia (NDH) and mild untreated diabetes in order to obtain a comprehensive understanding of the characteristics of the Si- $\beta$ correlation in the general population.

\section{Materials and Methods}

\section{Study design}

The study was approved by the Chikuma Central Hospital Review Board and the Aizawa Hospital Review Board. We analyzed data from health examinees. Those with renal failure (serum creatinine $>145$ $\mu \mathrm{M})$, liver cirrhosis, previous gastrointestinal operation or a known history of diabetes mellitus (DM) were excluded. Blood samples were obtained from 534 consecutive participants at 0,30 and 120 min during a standard $75 \mathrm{~g}$ oral glucose tolerance test (OGTT) for PG and serum immunoreactive insulin (IRI) measure- ments. In 1 subject, PG at 30 min was lower than FPG and therefore the index of $\beta$ cannot be calculated (see below). Accordingly, this person was excluded and the data from 533 subjects (male/female 367/166, and the mean age, BMI and FPG, 52.8 years, $23.6 \mathrm{~kg} / \mathrm{m}^{2}$ and $5.6 \mathrm{mM}$, respectively) were used for the study (Table 1). They formed part of the subject group analyzed in our previous studies [5,19], and therefore this study is a re-analysis of previously obtained data. PG was determined by the hexokinase method and IRI by a specific enzyme immunoassay [20].

\section{Classification of the participants}

In Analysis I, the participants were classified according to the current diagnostic criteria of diabetes and other categories of hyperglycemia [21] into NGT, NDH including impaired fasting glucose (IFG) and impaired glucose tolerance (IGT), and DM. The definition of each glucose tolerance category was as follows: NGT, FPG $\leq 6.0 \mathrm{mM}$ and 2-h post glucose PG $(2 \mathrm{hPG})$ at $75 \mathrm{~g}$ OGTT $<7.8 \mathrm{mM})$; IFG, FPG between

Table 1 Characteristics of the participants and Si- $\beta$ correlation and regression in Analysis I

\begin{tabular}{|c|c|c|c|c|}
\hline \multirow{2}{*}{ Variable } & \multirow{2}{*}{ All $(n=533)$} & \multicolumn{3}{|c|}{ Group } \\
\hline & & NGT $(n=328)$ & $\mathrm{NDH}(\mathrm{n}=133)$ & $\mathrm{DM}(\mathrm{n}=72)$ \\
\hline $\mathrm{M} / \mathrm{F}$ & $367 / 166$ & $227 / 101$ & $92 / 41$ & $48 / 24$ \\
\hline Age, yr & $52.8 \pm 11.3$ & $50.7 \pm 11.1$ & $55.3 \pm 10.9$ & $57.2 \pm 10.6$ \\
\hline $\mathrm{BMI}^{*}, \mathrm{~kg} / \mathrm{m}^{2}$ & $23.6 \pm 3.2(\mathrm{n}=502)$ & $23.2 \pm 3.0(\mathrm{n}=318)$ & $24.0 \pm 3.2(\mathrm{n}=118)$ & $25.3 \pm 3.5(\mathrm{n}=66)$ \\
\hline FPG, mM & $5.6 \pm 0.9$ & $5.2 \pm 0.4$ & $5.8 \pm 0.6$ & $7.2 \pm 1.2$ \\
\hline 2hPG, mM & $7.4 \pm 3.1$ & $5.8 \pm 1.0$ & $8.2 \pm 1.6$ & $13.7 \pm 3.7$ \\
\hline FIRI, pM & $38.2 \pm 25.7$ & $34.8 \pm 21.5$ & $42.4 \pm 27.1$ & $47.2 \pm 34.7$ \\
\hline 2hIRI, pM & $244.5 \pm 208.4$ & $194.6 \pm 153.6$ & $330.8 \pm 269.0$ & $309.1 \pm 232.7$ \\
\hline$\delta \mathrm{IRI}_{0-30} / \delta \mathrm{PG}_{0-30} \dagger$ & $0.62 \pm 0.75$ & $0.79 \pm 0.87$ & $0.45 \pm 0.39$ & $0.18 \pm 0.17$ \\
\hline $\mathrm{ISI}_{\text {Matsuda }}{ }^{\dagger}$ & $11.4 \pm 10.5$ & $14.1 \pm 11.4$ & $8.1 \pm 8.1$ & $5.3 \pm 4.1$ \\
\hline $\mathrm{DI}_{\mathrm{O}}$ & $7.0 \pm 11.0$ & $10.1 \pm 13.0$ & $2.7 \pm 2.4$ & $0.7 \pm 0.5$ \\
\hline \multicolumn{5}{|c|}{ Speraman's rank correlation } \\
\hline rho & -0.025 & $-0.201 \neq$ & -0.546 & -0.432 \\
\hline$p$ & 0.569 & $<0.001$ & $<0.001$ & 0.003 \\
\hline \multicolumn{5}{|c|}{ Standardized major axis regression } \\
\hline$a(95 \% \mathrm{CI})$ & N.A. & $9.991(7.189 \sim 13.885)$ & $2.996(2.100 \sim 4.273)$ & $1.065(0.625 \sim 1.814)$ \\
\hline$b(95 \% \mathrm{CI})$ & N.A. & $-1.205(-1.340 \sim-1.083)$ & $-1.216(-1.407 \sim-1.050)$ & $-1.530(-1.892 \sim-1.238)$ \\
\hline$r^{2}$ & N.A. & 0.039 & 0.277 & 0.193 \\
\hline$p$ & N.A. & $<0.001$ & $<0.001$ & $<0.001$ \\
\hline
\end{tabular}

Plus-minus values are mean \pm SD. M/F. male/female; BMI, body mass index; 2hPG, 2-h post glucose PG at $75 \mathrm{~g}$ oral glucose tolerance test (OGTT); FIRI, fasting immunoreactive insulin (IRI); 2hIRI, 2-h post glucose IRI at $75 \mathrm{~g}$ OGTT; $\mathrm{DI}_{\mathrm{O}}$, oral disposition index; N.A., not applicable; CI, confidence interval; *, BMI data is missing in 31 subjects so that the number of subjects with BMI value is indicated in the parentheses; $\uparrow$, conventional units were used for $\delta \mathrm{IRI}_{0-30} / \delta \mathrm{PG}_{0-30}$ and ISI Matsuda $_{2}[\mu \mathrm{U} / \mathrm{mL}] /[\mathrm{mg} / 100 \mathrm{~mL}]$ and $[\mu \mathrm{U} / \mathrm{mL}]^{-1} \cdot[\mathrm{mg} / 100 \mathrm{~mL}]^{-1}$, respectively, as in the original reports $[22,24] ;$;, significantly different $(p=0.003)$ from the corresponding value in NDH. By Kruscal-Wallis test, age, BMI, FIRI, 2hIRI, $\delta \mathrm{IRI}_{0-30} / \delta \mathrm{PG}_{0-30}, \mathrm{ISI}_{\text {Matsuda }}$ and $\mathrm{DI}_{\mathrm{O}}$ in $\mathrm{NGT}, \mathrm{NDH}$ and $\mathrm{DM}$ were all significantly different $(p<0.001$ for all variables except for FIRI for which $p=0.001$ ). 
$\geq 6.1 \mathrm{mM}$ and $<7.0 \mathrm{mM}$, and $2 \mathrm{hPG}<7.8 \mathrm{mM}$ ); IGT, $\mathrm{FPG}<7.0 \mathrm{mM}$ and $2 \mathrm{hPG}$ between $\geq 7.8$ and $<11.1 \mathrm{mM}$ ); $\mathrm{DM}, \mathrm{FPG} \geq 7.0 \mathrm{mM}$ and/or $2 \mathrm{hPG} \geq 11.1 \mathrm{mM}$. The number of subjects in each group was 328 in NGT, 133 in $\mathrm{NDH}$ and 72 in DM.

Si- $\beta$ correlation was weakest in NGT group (see below). Therefore, factors associated with poor $\mathrm{Si}-\beta$ correlation were sought among subjects with NGT. Because low FPG and BMI were independently correlated with degree of deviation from the regression curve (see below at "Identification of variables related to deviation from the hyperbolic regression in subjects with NGT"), subjects with NGT were subdivided on the basis of FPG tertile and BMI tertile. Namely, $\operatorname{NGT}_{\mathrm{FPG} 1}(\mathrm{n}=103), \mathrm{NGT}_{\mathrm{FPG} 2}(\mathrm{n}=118)$ and $\mathrm{NGT}_{\mathrm{FPG} 3}$ $(\mathrm{n}=107)$ by FPG tertile $(\leq 4.9,5.0-5.4$ and $5.5-6.0 \mathrm{mM})$, or $\mathrm{NGT}_{\text {BMI1 }}(\mathrm{n}=106), \mathrm{NGT}_{\mathrm{BMI} 2}(\mathrm{n}=103)$ and $\mathrm{NGT}_{\mathrm{BMI} 3}$ $(\mathrm{n}=109)$ by BMI tertile $(\leq 21.8,21.9-24.4$ and $\geq 24.5 \mathrm{~kg} /$ $\mathrm{m}^{2}$ ). FPG tertile and BMI tertile were selected as the closest to the equal 3 division of the subjects. BMI values were missing in 10 subjects, so that the number of subjects analyzed by BMI tertile was 318 .

\section{Parameters}

As a measure of $\mathrm{Si}$, the insulin sensitivity index proposed by Matsuda [22] (ISI Matsuda $_{\text {) was }}$ calculated by using fasting and 2-h post glucose blood samples during 75 g OGTT [23], i.e., ISI $_{\text {Matsuda }}=10,000$ / sqrt[FPG·FIRI·2hPG·2hIRI], where FIRI was fasting IRI and 2hIRI was 2-h post glucose IRI. Correlation between clamp-based Si and ISI $_{\text {Matsuda }}$ obtained by a modified method [23] was reportedly slightly stronger than that between clamp-based Si and ISI $_{\text {Matsuda }}$ in the original study [22]. As an index of $\beta, \delta \mathrm{IRI}_{0-30} / \delta \mathrm{PG}_{0-30}$ during $75 \mathrm{~g}$ OGTT [24] was adopted. As another index of $\beta$, the Stumvoll index (first phase) [25] was used in some analyses. The equation for the index was, $1283+1.829 \cdot\left[\mathrm{IRI}_{30}\right]-138.7 \cdot\left[\mathrm{PG}_{30}\right]+3.772 \cdot[\mathrm{FIRI}]$, where $\mathrm{IRI}_{30}$ and $\mathrm{PG}_{30}$ were 30 -min post glucose IRI and PG during 75g OGTT, respectively [25]. Analysis using the Stumvoll index was performed in the groups of subjects with NDH and NGT, and in the NGT subgroups, because the index was formulated using data from non-diabetic subjects [25]. Strong linear correlations were established between insulin sensitivity measured by euglycemic clamp and $\operatorname{ISI}_{\text {Matsuda }}(r=0.73)$ [22], between acute insulin release (AIR) upon intravenous glucose injection and $\delta \mathrm{IRI}_{0-30} / \delta \mathrm{PG}_{0-30}(r=0.88)$ [26], and between AIR and the Stumvoll index $(r=0.79)$
[25]. A product of $\mathrm{ISI}_{\text {Matsuda }}$ and $\delta \mathrm{IRI}_{0-30} / \delta \mathrm{PG}_{0-30}$ was obtained as an oral disposition index $\mathrm{DI}\left(\mathrm{DI}_{\mathrm{O}}\right)[18,27]$, a measure of beta cell function with the degree of insulin sensitivity being taken into account.

\section{Statistics}

The bivariate correlation between Si and $\beta$ was evaluated by Spearman's rank correlation. The parameters of the power regression, $\left[\delta \mathrm{IRI}_{0-30} / \delta \mathrm{PG}_{0-30}\right]=a \cdot\left[\mathrm{ISI}_{\text {Matsuda }}\right]^{b}$, were obtained by standardized major axis (SMA) regression [28]. We ascertained that the distribution of log-transformed ISI $\mathrm{I}_{\text {Matsuda }}$ and $\delta \mathrm{IRI}_{0-30} / \delta \mathrm{PG}_{0-30}$ in each group was not significantly different from the normal distribution. Accordingly, using log-transformed ISI $_{\text {Matsuda }}$ and log-transformed $\delta \mathrm{IRI}_{0-30} / \delta \mathrm{PG}_{0-30}$, SMA regression was applied, i.e., $\log \left[\delta \mathrm{IRI}_{0-30} / \delta \mathrm{PG}_{0-}\right.$ $\left.{ }_{30}\right]=\log (a)+b \cdot \log \left[\right.$ ISI $\left._{\text {Matsuda }}\right]$ was calculated. SMA regression was performed using SMATR ver 2.0 [29]. The SMA regression slope parameters, $b$, for 2 or 3 groups were compared by using a likelihood ratio test [30]. Because there were no significant differences between the slopes, $b$, for NGT, NDH and DM, or between those for $\mathrm{NGT}_{\mathrm{FPG} 2}$ and $\mathrm{NGT}_{\mathrm{FPG} 3}$, a common slope was calculated for NGT, NDH and DM, or $\mathrm{NGT}_{\mathrm{FPG} 2}$ and $\mathrm{NGT}_{\mathrm{FPG} 3}[29,30]$. Subsequently, intercept, $a$, with "the common slope" was compared across the groups by using all-pair comparisons as an ad hoc method of analysis. Adjustment of multiplicity was performed by the Holm method [31]. The orthogonal distance from the regression line to each data point was calculated by the following formula.

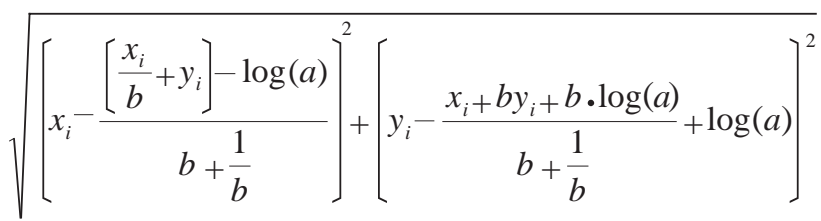

where $x_{i}, y_{i}, b$ and $\log (a)$ were $\log \left[\right.$ ISI $\left._{\text {Matsuda] }}\right]$ $\log \left[\delta \mathrm{IRI}_{0-30} / \delta \mathrm{PG}_{0-30}\right]$, the slope and intercept of SMA regression, respectively.

Other statistical analyses were performed using StatView $\left(\mathrm{SAS}^{\circledR}\right.$ ) and $p<0.05$ was considered significant. Statistical comparison of correlation coefficients was performed after Fisher's Z transformation.

\section{Results}

\section{Analysis I}

Characteristics of subjects with NGT, NDH and DM

The mean FPG and 2hPG were lowest in NGT and progressively higher in NDH and DM as defined (Table 
$1)$. On the contrary, the mean values for $\delta \mathrm{IRI}_{0-30} /$ $\delta \mathrm{PG}_{0-30}, \mathrm{ISI}_{\text {Matsuda }}$ and $\mathrm{DI}_{\mathrm{O}}$ were highest in NGT and progressively lower with worsening of glucose tolerance. The mean age and BMI were lowest in NGT and progressively higher in NDH and DM. The difference was statistically significant for all of these variables (Table 1).

\section{Correlation between $\mathrm{Si}$ and $\beta$}

According to Spearman's rank correlation, significant correlation between $\mathrm{ISI}_{\text {Matsuda }}$ and $\delta \mathrm{IRI}_{0-30} /$ $\delta \mathrm{PG}_{0-30}$ was present in NGT, NDH and DM (Table 1). Rather unexpectedly, correlation between ISI $_{\text {Matsuda }}$ and $\delta \mathrm{IRI}_{0-30} / \delta \mathrm{PG}_{0-30}$ was strongest (Spearman's rho=$0.546)$ in NDH, intermediate (-0.432) in DM, and weakest $(-0.201)$ in NGT, with the difference of rho between NGT and NDH being highly significant $(p=0.003)$. Correlation between ISI $_{\text {Matsuda }}$ and the Stumvoll index was also stronger in NDH (Spearman's rho=-0.614) than in NGT $(-0.408)$. The rho values were significantly different $(p=0.039)$.

SMA regression showed that regression was significant in all three groups: it was strongest $\left(r^{2}\right.$ for SMA regression $=0.277)$ in $\mathrm{NDH}$, intermediate $\left(r^{2}=0.193\right)$ in DM, and weak $\left(r^{2}=0.039\right)$ in NGT. The parameters of regression for $\mathrm{ISI}_{\text {Matsuda }}$ to $\delta \mathrm{IRI}_{0-30} / \delta \mathrm{PG}_{0-30}$, $\log \left[\delta \mathrm{IRI}_{0-30} / \delta \mathrm{PG}_{0-30}\right]=\log (a)+b \cdot \log \left[\mathrm{ISI}_{\text {Matsuda }}\right]$, are shown in Table 1. $b$ was $-1.205,-1.530$, and -1.216 , in NGT, NDH, and DM respectively, and the values were not significantly different from each other: the slope common to the three groups was $b=-1.250$. $a$ obtained by SMA regression was 9.991, 2.996 and 1.065, in NGT, $\mathrm{NDH}$, and DM respectively. $a$ with the common slope, $b=-1.250$, was $11.145,3.190$ and 0.712 in NGT, NDH and DM respectively, and the values were significantly different from each other $(p<0.001)$. The finding was compatible with reduced $\mathrm{DI}_{\mathrm{O}}$ in $\mathrm{NDH}$ and $\mathrm{DM}$ compared to NGT (Table 1). As shown in Fig. 1, the bestfit regression line for $\left[\delta \mathrm{IRI}_{0-30} / \delta \mathrm{PG}_{0-30}\right]=a \cdot\left[\mathrm{ISI}_{\text {Matsuda }}\right]^{b}$ was progressively closer to the origin of the graph from NGT to DM.

Identification of variables related to deviation from the hyperbolic regression in subjects with NGT

FPG, 2hPG and BMI but not age showed significant inverse correlation with orthogonal distance from the regression line obtained by SMA regression. However, the variability of $2 \mathrm{hPG}$ during $75 \mathrm{~g}$ OGTT is substantially greater than that of FPG [32], so that $2 \mathrm{hPG}$ was considered to be unsuitable as a variable to classify subjects with NGT. In multivariate analysis, both FPG
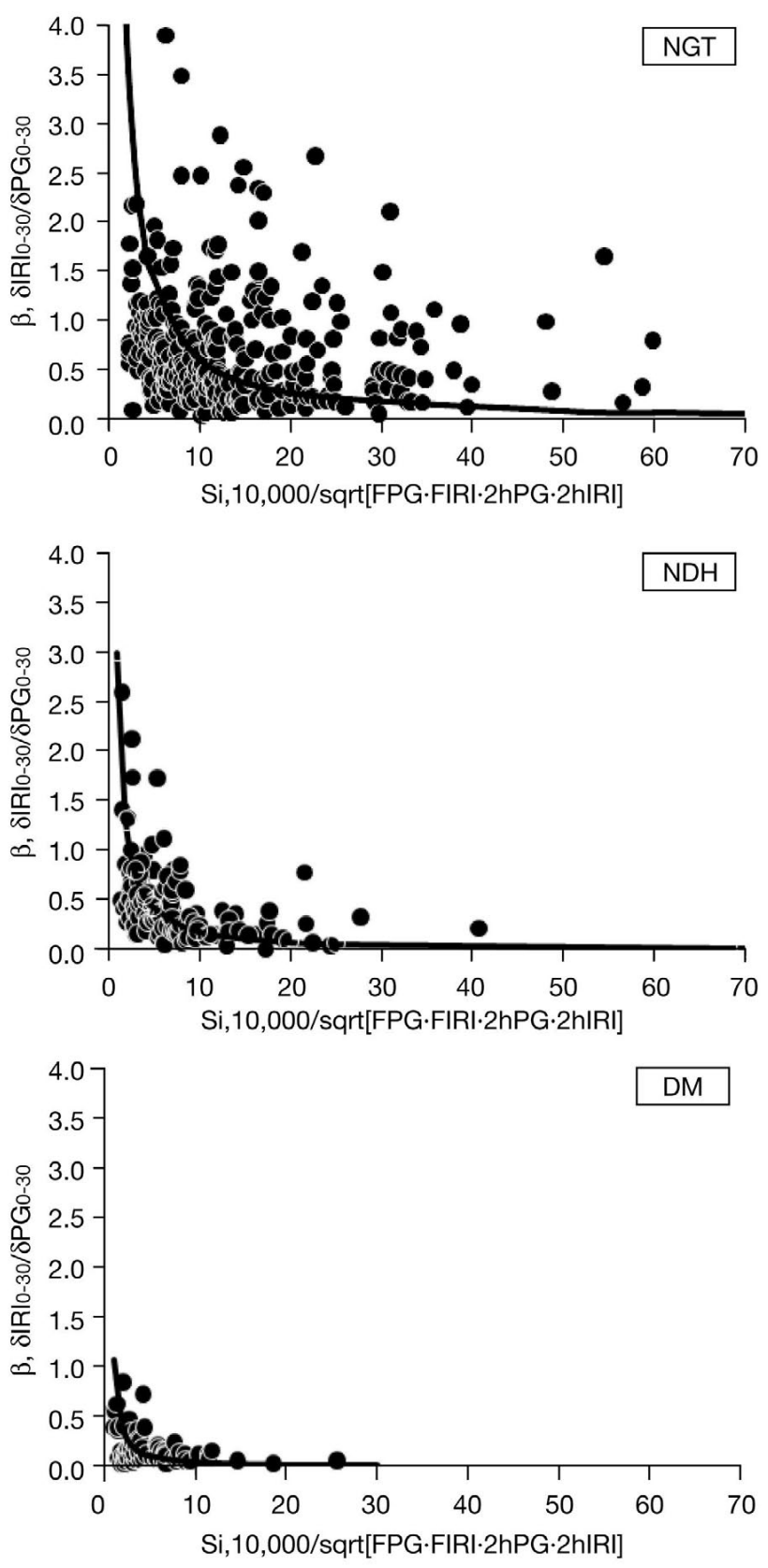

Fig. 1 Correlation between $\mathrm{Si}$ and $\beta$ in each group in Analysis I. The curvilinear element is the best-fit regression line for $\left[\delta \mathrm{IRI}_{0-30} / \delta \mathrm{PG}_{0-30}\right]=a \cdot\left[\mathrm{ISI}_{\text {Matsuda }}\right]^{b}$ obtained from all values in each group by standardized major axis regression. To facillitate visual comparison across the groups, graphs with the same $y(0-4)$ and $x(0-70)$ axes for all groups are shown. Accordingly, symbols for the individuals with $\beta>4.0$ and/ or $\mathrm{Si}>70$ in metric units $(\mathrm{n}=6 ; 5$ in NGT and 1 in NDH) are not shown. 

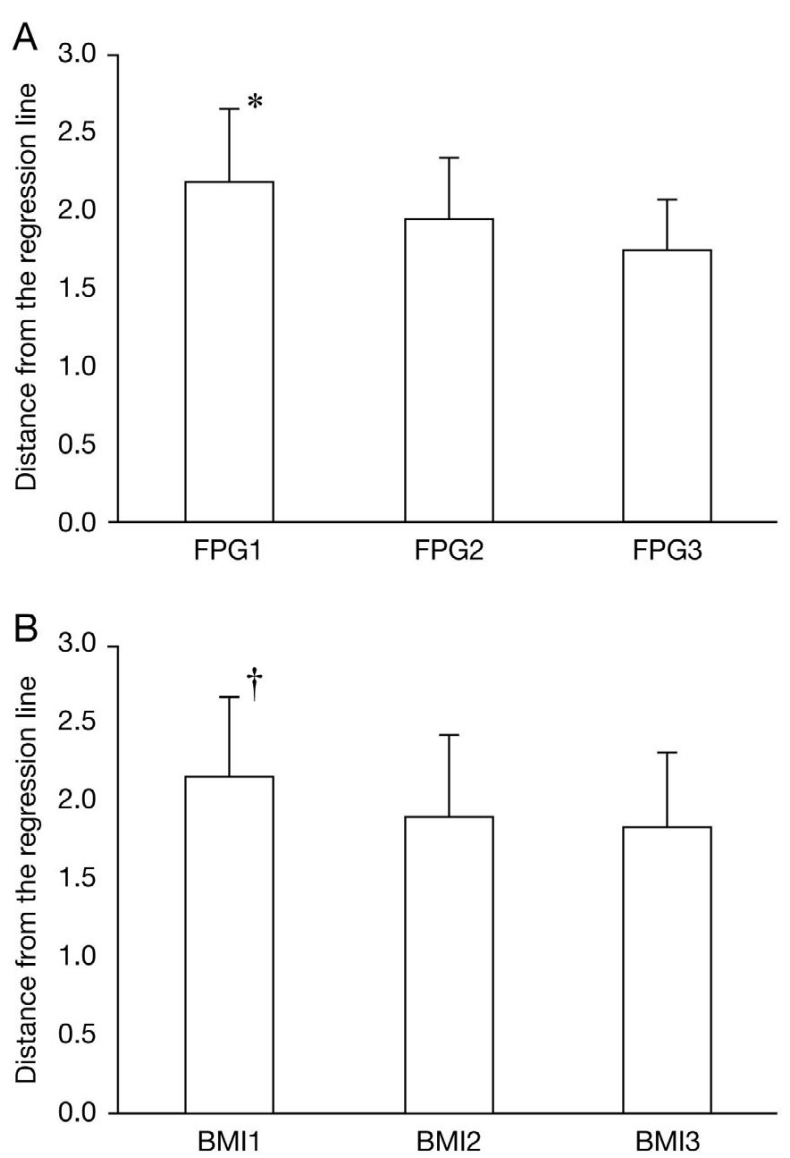

Fig. 2 Distance from the regression line in NGT subgroups. Values are mean+SD. Orthogonal distance from the regression line to each data point was calculated by the following formula.

$\sqrt{\left[x_{i}-\frac{\left[\frac{x_{i}}{b}+y_{i}\right]-\log (a)}{b+\frac{1}{b}}\right]^{2}+\left[y_{i}-\frac{x_{i}+b y_{i}+b \cdot \log (a)}{b+\frac{1}{b}}+\log (a)\right]^{2}}$

where $x_{i}, y_{i}, b$ and $\log (a)$ were $\log \left[\right.$ ISI $\left._{\text {Matsuda }}\right], \log \left[\delta \mathrm{IRI}_{0 \text { - }}\right.$ $\left.{ }_{30} / \delta \mathrm{PG}_{0-30}\right]$, the slope and intercept of SMA regression, respectively. A. FPG tertile; FPG1, NGT $\mathrm{FPG}_{1}$; FPG2, $\mathrm{NGT}_{\mathrm{FPG} 2} ; \mathrm{FGP3}, \mathrm{NGT}_{\mathrm{FPG} 3}$. B. BMI tertile; BMI,

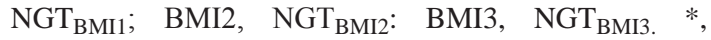
significantly different from FPG2 and FPG3, and $\dagger$, significantly different from BMI3 (ANOVA followed by Scheffe test).

$(p<0.001)$ and BMI $(p<0.001)$ were independently correlated with distance from the regression line. On the basis of this finding, subjects with NGT were subdivided by FPG or BMI tertile. As expected, the distance from the regression line in the lowest tertile was significantly larger than in the higher tertiles in the case of both FPG and BMI (Fig. 2).

\section{Analysis II}

Characteristics of subjects in NGT subgroups

The mean 2hPG was lowest in $\mathrm{NGT}_{\mathrm{FPG} 1}$ and progressively higher in $\mathrm{NGT}_{\mathrm{FPG} 2}$ and $\mathrm{NGT}_{\mathrm{FPG} 3}$ (Table 2). On the contrary, the mean values for $\delta \mathrm{IRI}_{0-30} / \delta \mathrm{PG}_{0-30}$, ISI $_{\text {Matsuda }}$ and $\mathrm{DI}_{\mathrm{O}}$ were highest in $\mathrm{NGT}_{\mathrm{FPG} 1}$ and progressively lower with elevation of FPG. The mean age and $\mathrm{BMI}$ were lowest in $\mathrm{NGT}_{\mathrm{FPG} 1}$ and progressively higher in $\mathrm{NGT}_{\mathrm{FPG} 2}$ and $\mathrm{NGT}_{\mathrm{FPG} 3}$. The difference was statistically significant except for age (Table 2)

Both FPG and 2hPG were progressively higher from $\mathrm{NGT}_{\mathrm{BMI} 1}$ to $\mathrm{NGT}_{\mathrm{BMI} 3}$. ISI $\mathrm{I}_{\text {Matsuda }}$ and $\mathrm{DI}_{\mathrm{O}}$ were highest in $\mathrm{NGT}_{\mathrm{BMI} 1}$ and progressively lower in $\mathrm{NGT}_{\mathrm{BMI} 2}$ and $\mathrm{NGT}_{\mathrm{BMI} 3}$. The differences in these variables across the 3 groups were statistically significant (Table $2)$. But there were no significant differences in age or $\delta \mathrm{IRI}_{0-30} / \delta \mathrm{PG}_{0-30}$.

The larger coefficient of variation $(\mathrm{SD} /$ mean) for $\mathrm{DI}_{\mathrm{O}}$ in the lowest FPG and BMI tertile compared with the respective higher tertiles indicates successful segregation of subjects with greater deviation from the regression by FPG and BMI tertiles (Table 2).

\section{Correlation between $\mathrm{Si}$ and $\beta$}

Statistically significant bivariate correlation between ISI $_{\text {Matsuda }}$ and $\delta \mathrm{IRI}_{0-30} / \delta \mathrm{PG}_{0-30}$ was present in $\mathrm{NGT}_{\mathrm{FPG} 3}$ and NGT FPG2 $_{\text {but not in NGT }}$ FPG1 (Table 2). The correlation between the two variables was statistically significant in $\mathrm{NGT}_{\mathrm{BMI}}$ but not in $\mathrm{NGT}_{\mathrm{BMI} 2}$ or $\mathrm{NGT}_{\mathrm{BMI}}$ (Table 2). The correlation between ISI $_{\text {Matsuda }}$ and the Stumvoll index was significant $(p<0.001$ for all groups) in all FPG tertiles with Spearman's rho being smallest in $\mathrm{NGT}_{\mathrm{FPG} 1}$, i.e., -0.534 in $\mathrm{NGT}_{\mathrm{FPG} 3},-0.606$ in $\mathrm{NGT}_{\mathrm{FPG} 2}$ and -0.451 in $\mathrm{NGT}_{\mathrm{FPG} 1}$. The correlation

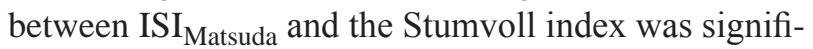
cant in $\mathrm{NGT}_{\mathrm{BMI} 3}(\mathrm{rho}=-0.493, p<0.001)$ and $\mathrm{NGT}_{\mathrm{BMI} 2}$ $(\mathrm{rho}=-0.450, p<0.001)$ but not in $\mathrm{NGT}_{\mathrm{BMI} 1}(\mathrm{rho}=-0.163$, $p=0.094)$. Bivariate correlation between ISI $_{\text {Matsuda }}$ and $\delta \mathrm{IRI}_{0-30} / \delta \mathrm{PG}_{0-30}$ was stronger in the $3^{\text {rd }} \mathrm{FPG}$ and $\mathrm{BMI}$ tertiles than in the entire NGT population as indicated by the greater rho in the $3^{\text {rd }}$ tertiles: the difference was not statistically significant though.

Using SMA regression, statistically significant regression was obtained in $\mathrm{NGT}_{\mathrm{FPG} 3}, \mathrm{NGT}_{\mathrm{FPG} 2}$ and $\mathrm{NGT}_{\mathrm{BMI} 3}$ (Table 2). The parameters of SMA regression for $\mathrm{ISI}_{\text {Matsuda }}$ to $\delta \mathrm{IRI}_{0-30} / \delta \mathrm{PG}_{0-30}, \log \left[\delta \mathrm{IRI}_{0-30} / \delta \mathrm{PG}_{0-30}\right]$ $=\log \left[(a)+b \cdot \log \left[\right.\right.$ ISI $\left._{\text {Matsuda }}\right]$, were as follows (Table 2). $b$ was -1.184 in $\mathrm{NGT}_{\mathrm{FPG} 2}$ and -1.334 in $\mathrm{NGT}_{\mathrm{FPG} 3}$, values which were not significantly different, and the common slope was $b=-1.253$. $a$ by respective SMA regres- 
Table 2 Characteristics of the participants and Si- $\beta$ correlation and regression in Analysis II (NGT subgroup analysis)

\begin{tabular}{|c|c|c|c|c|c|c|}
\hline \multirow{2}{*}{ Variable } & \multicolumn{3}{|c|}{ FPG tertiles } & \multicolumn{3}{|c|}{ BMI tertiles } \\
\hline & $\mathrm{NGT}_{\mathrm{FPG} 1}(\mathrm{n}=103)$ & $\mathrm{NGT}_{\mathrm{FPG} 2}(\mathrm{n}=118)$ & $\mathrm{NGT}_{\mathrm{FPG} 3}(\mathrm{n}=107)$ & $\operatorname{NGT}_{\text {BMI1 }}(\mathrm{n}=106)$ & $\mathrm{NGT}_{\text {BMI2 }}(\mathrm{n}=103)$ & $\mathrm{NGT}_{\text {BMI3 }}(\mathrm{n}=109)$ \\
\hline$\overline{\mathrm{M} / \mathrm{F}}$ & $56 / 47$ & $88 / 30$ & $83 / 24$ & $68 / 38$ & $68 / 35$ & $85 / 24$ \\
\hline Age, yr & $49.3 \pm 11.7$ & $50.6 \pm 10.5$ & $52.3 \pm 11.0$ & $50.3 \pm 12.0$ & $51.5 \pm 10.1$ & $50.3 \pm 10 . .6$ \\
\hline $\mathrm{BMI}^{*}, \mathrm{~kg} / \mathrm{m}^{2}$ & $22.3 \pm 2.9(\mathrm{n}=100)$ & $23.2 \pm 2.9(\mathrm{n}=116)$ & $24.0 \pm 3.0(\mathrm{n}=102)$ & $20.0 \pm 1.4$ & $23.0 \pm 0.7$ & $26.4 \pm 1.8$ \\
\hline FPG, mM & $4.7 \pm 0.2$ & $5.2 \pm 0.1$ & $5.7 \pm 0.2$ & $5.1 \pm 0.4$ & $5.2 \pm 0.4$ & $5.3 \pm 0.4$ \\
\hline 2hPG, mM & $5.4 \pm 1.1$ & $5.8 \pm 1.0$ & $6.1 \pm 0.9$ & $5.5 \pm 1.0$ & $5.9 \pm 1.0$ & $6.0 \pm 1.0$ \\
\hline FIRI, pM & $31.3 \pm 18.1$ & $34.0 \pm 22.9$ & $37.5 \pm 23.6$ & $22.5 \pm 13.0$ & $35.4 \pm 18.5$ & $45.2 \pm 25.6$ \\
\hline 2hIRI, pM & $163.9 \pm 139.6$ & $197.9 \pm 148.6$ & $221.5 \pm 166.7$ & $123.1 \pm 72.6$ & $205.7 \pm 151.6$ & $258.1 \pm 185.0$ \\
\hline$\delta \mathrm{IRI}_{0-30} / \delta \mathrm{PG}_{0-30} \dagger$ & $1.00 \pm 1.07$ & $0.76 \pm 0.60$ & $0.62 \pm 0.86$ & $0.75 \pm 0.75$ & $0.74 \pm 0.61$ & $0.89 \pm 1.16$ \\
\hline $\operatorname{ISI}_{\text {Matsuda }} \dagger$ & $17.3 \pm 12.1$ & $14.4 \pm 13.3$ & $10.6 \pm 6.7$ & $20.4 \pm 14.7$ & $12.1 \pm 7.7$ & $9.5 \pm 7.0$ \\
\hline $\mathrm{DI}_{\mathrm{O}}$ & $15.9 \pm 18.5$ & $9.1 \pm 9.2$ & $5.6 \pm 7.0$ & $14.7 \pm 17.5$ & $8.6 \pm 10.0$ & $7.2 \pm 9.2$ \\
\hline \multicolumn{7}{|c|}{ Spearman's rank correlation } \\
\hline rho & -0.129 & -0.383 & -0.344 & -0.044 & -0.170 & -0.313 \\
\hline$p$ & 0.1926 & $<0.001$ & $<0.001$ & 0.654 & 0.086 & 0.001 \\
\hline \multicolumn{7}{|c|}{ Standardized major axis regression } \\
\hline$a(95 \% \mathrm{CI})$ & N.A. & $9.557(5.686 \sim 16.131)$ & $7.845(4.494 \sim 13.693)$ & N.A. & N.A. & $11.112(6.315 \sim 19.531)$ \\
\hline$b(95 \% \mathrm{CI})$ & N.A. & $-1.184(-1.408 \sim-0.997)$ & $-1.334(-1.599 \sim-1.114)$ & N.A. & N.A. & $-1.426(-1.707 \sim-1.191)$ \\
\hline$r^{2}$ & N.A. & 0.118 & 0.119 & N.A. & N.A. & 0.108 \\
\hline$p$ & N.A. & $<0.001$ & $<0.001$ & N.A. & N.A. & $<0.001$ \\
\hline
\end{tabular}

Plus-minus values are mean \pm SD. Abbreviations are the same as in Table $1 .{ }^{*}$, BMI data is missing in 10 subjects so that the number of subjects with BMI value is indicated in the parentheses for FPG tertiles; $\uparrow$, conventional units were used for $\delta \mathrm{IRI}_{0-30} / \delta \mathrm{PG}_{0-30}$ and ISI $_{\text {Matsuda, }}[\mu \mathrm{U} / \mathrm{mL}] /[\mathrm{mg} / 100 \mathrm{~mL}]$ and $\left[\mu \mathrm{U} / \mathrm{mL}^{-1} \cdot[\mathrm{mg} / 100 \mathrm{~mL}]^{-1}\right.$, respectively, as in the original reports $[22,24]$. In FPG tertiles, by Kruscal-Wallis test, BMI, 2hIRI, $\delta \mathrm{IRI}_{0-30} / \delta \mathrm{PG}_{0-30}, \mathrm{ISI}_{\text {Matsuda }}$ and $\mathrm{DI}_{\mathrm{O}}$ in FPG tertiles were all significantly different $(p<0.001$ for all variables except for $2 \mathrm{hPG}$ for which $p=0.003$ ). In BMI tertiles, FPG, 2hPG, FIRI, 2hIRI, ISI $\mathrm{Matsuda}_{\text {and }} \mathrm{DI}_{\mathrm{O}}$ were significantly different $(p<0.001$ for all variables).

sion was 9.557 in $\mathrm{NGT}_{\mathrm{FPG} 2}$ and 7.845 in $\mathrm{NGT}_{\mathrm{FPG} 3}$. $a$ with the common slope, $b=-1.253$, was 11.314 and 6.573 for $\mathrm{NGT}_{\mathrm{FPG} 2}$ and $\mathrm{NGT}_{\mathrm{FPG} 3}$ respectively, and the values were significantly different $(p<0.001)$. The finding is compatible with $\mathrm{DI}_{\mathrm{O}}$ being lower in the latter than in the former (Table 2). The parameters of regression in $\mathrm{NGT}_{\mathrm{BMI} 3}$ were as follows: $b=-1.426$ and $a=11.112$. As shown in Fig. 3A, the best-fit regression line for $\left[\delta \mathrm{IRI}_{0-30} / \delta \mathrm{PG}_{0-30}\right]=a \cdot\left[\mathrm{ISI}_{\text {Matsuda }}\right]^{b}$ in $\mathrm{NGT}_{\mathrm{BMI} 3}$ lies relatively close to the origin (Fig. 3).

\section{Discussion}

In this study, we confirmed the fundamental characteristic of the Si- $\beta$ correlation across glucose tolerance categories, i.e., progressive left and downward shifting of the hyperbolic regression curve and lowering of DI with worsening of glucose tolerance [1-4]. The novel findings in this study are as follows. Firstly, Si- $\beta$ inverse correlation was strongest in $\mathrm{NDH}$, intermediate in DM and weakest in NGT. The weak Si- $\beta$ correlation in DM was to be expected because both insulin sensitivity and beta cell function deteriorate to vary- ing degrees in patients with diabetes. However, the significant weakening of the Si- $\beta$ correlation in NGT compared to NDH was unexpected because beta cell adaptation to altered insulin sensitivity is thought to be most robust in subjects with NGT. This was the case not only for the relationship between ISI $_{\text {Matsuda }}$ and $\delta \mathrm{IRI}_{0-30} / \delta \mathrm{PG}_{0-30}$, but also for the relationship between ISI $_{\text {Matsuda }}$ and the Stumvoll index. If distribution of PG values, FPG and 2hPG, in subjects with NGT had been significantly wider than the distribution of the corresponding values in NDH, it would have implied that the subjects in NGT were more heterogeneous than those in NDH with respect to glucose regulation. Then, the Si- $\beta$ correlation in NGT would have been weaker than that in NDH. However, the coefficient of variation for FPG and 2hPG was consistently lower in NGT than in $\mathrm{NDH}$, which ruled out any such possibility (Table 1).

Secondly, we hypothesized that the Si- $\beta$ correlation is very poor or insignificant in a certain group of subjects with NGT, thereby making the correlation in the entire NGT group weak. Using orthogonal distance from the regression line as a quantitative index of deviation, we found that lower BMI and FPG were inde- 

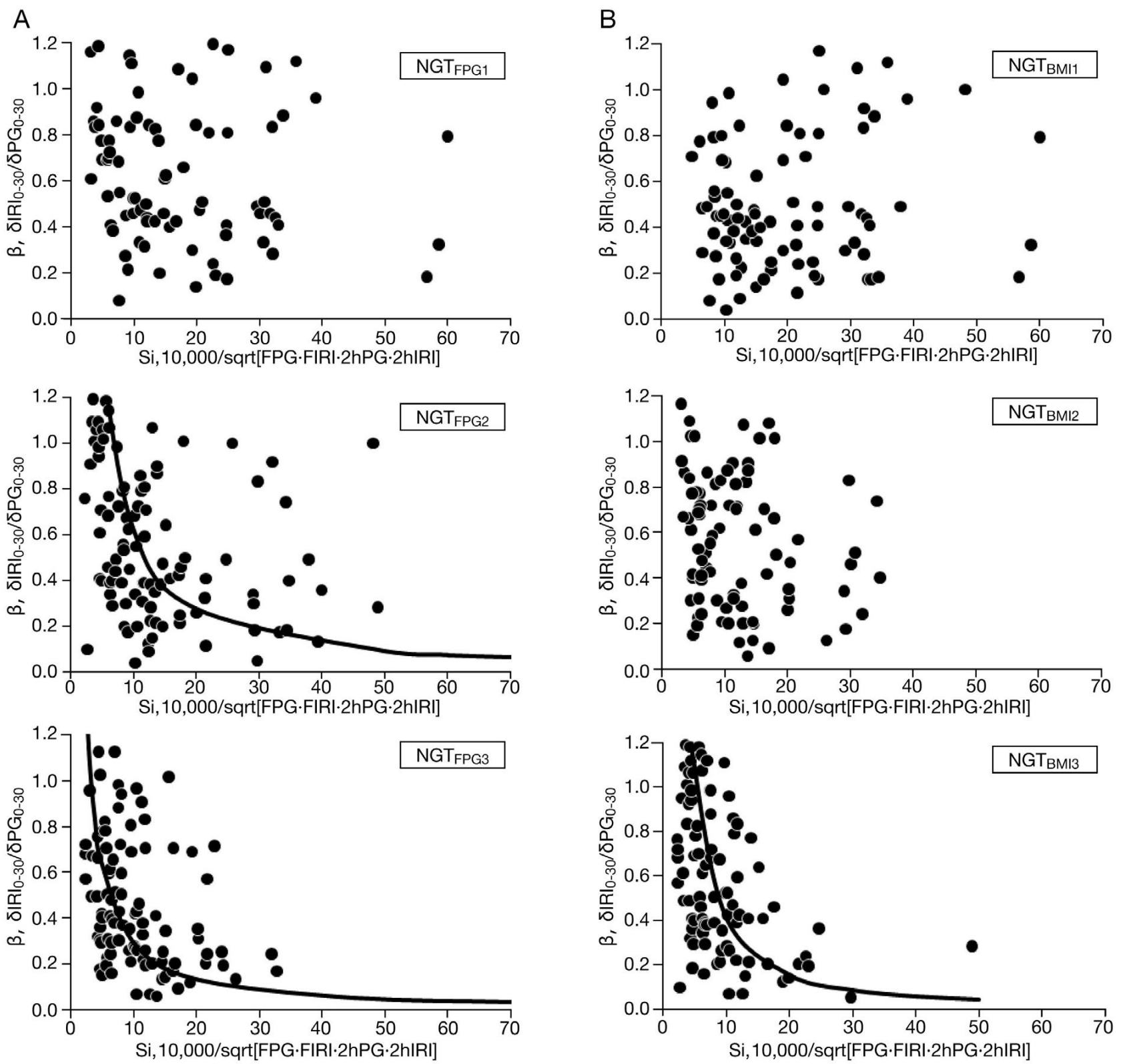

Fig. 3 Correlation between Si and $\beta$ in each group in Analysis II (NGT subgroup analysis).

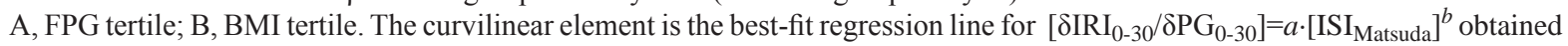
from all values in each group by standardized major axis regression. There was no significant bivariate correlation between Si and $\beta$ in $\mathrm{NGT}_{\mathrm{FPG} 1}, \mathrm{NGT}_{\mathrm{BMI} 1}$ and $\mathrm{NGT}_{\mathrm{BMI} 2}$. To facillitate visual comparison across the groups, graphs with the same $y(0-1.2)$ and $x$ (0-70) axes for all groups are shown. Accordingly, symbols for the individuals with $\beta>1.2$ and/or $\mathrm{Si}>70$ in metric units are not

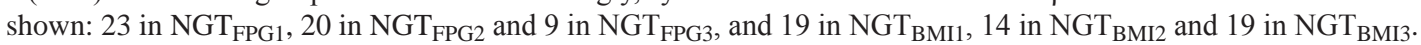

pendently associated with the deviation. Moreover, any significant inverse Si- $\beta$ correlation in the lowest BMI tertile was found to have disappeared. This was also the case not only for the relationship between $\mathrm{ISI}_{\text {Matsuda }}$ and $\delta \mathrm{IRI}_{0-30} / \delta \mathrm{PG}_{0-30}$, but also for the relationship between ISI $_{\text {Matsuda }}$ and the Stumvoll index.
ISI $_{\text {Matsuda }}$ contains 1/sqrt[FIRI], 1/sqrt[2hPG] and 1/ sqrt[2hIRI], so that it is not surprising that it correlates more robustly with the Stumvoll index than $\delta \mathrm{IRI}_{0-30} /$ $\delta \mathrm{PG}_{0-30}$. The fading of any significant $\mathrm{Si}-\beta$ inverse correlation in the lowest FPG tertile was not as clear as that in the lowest BMI tertile because the correla- 
tion was significant when the Stumvoll index was used in the place of $\delta \mathrm{IRI}_{0-30} / \delta \mathrm{PG}_{0-30}$. Lower BMI in lower NGT tertiles may be an important factor in the weakening of the Si- $\beta$ inverse correlation. Nevertheless, it is of note that the $\mathrm{Si}-\beta$ correlation in NDH subjects $(\mathrm{n}=49)$ with BMI values matched to those in $\mathrm{NGT}_{\mathrm{BMI}}$ was highly significant $(p=0.003)$, indicating that lowest BMI tertile and NGT are required for diminution of the Si- $\beta$ correlation. In other words, for increased insulin secretion to occur, relatively high BMI or relatively high glycemia may be needed.

Lastly, in all groups with significant inverse correlation between $\mathrm{Si}$ and $\beta, 95 \% \mathrm{CI}$ of the slope $b$ of $[\beta]=a \cdot[\mathrm{Si}]^{b}$ exceeded -1 , except for $\mathrm{NGT}_{\mathrm{FPG} 2}$ in which -1 was included in the $95 \%$ CI of $b$. We consider that the $\mathrm{Si}-\beta$ regression is generally not significantly different from the hyperbola because the upper limit of $95 \%$ CI did not exceed -2 .

The weak Si- $\beta$ correlation in NGT subjects may be due to the presence of a confounding factor or factors which favorably affect glucose metabolism. Glucose effectiveness (Sg) and the incretin effect may be such factors [1]. Sg is the mass action of glucose itself [1, 33], i.e., insulin-independent, glucose-mediated, glucose disposal. Among subjects with NGT, stronger Sg is associated with lower glycemia, larger $\beta$, and higher $\mathrm{Si}$ [34]. With stronger $\mathrm{Sg}, \mathrm{PG}$ is lower at a given level of IRI, and overestimation of $\mathrm{Si}$ would ensue. Incretins are gut-derived peptides such as glucagon-like peptide-1, which augment insulin secretion in a glucose-dependent manner [35]. The incretin effect is progressively stronger with lower FPG in subjects with NGT [36]. A stronger incretin effect may result in overestimation of $\beta$. Notably, incretin enhances $\mathrm{Sg}$ [37], and therefore the two are synergistic. Taken together, both Sg and the incretin effect may be strong in a certain number of subjects with NGT, so that the statistical significance of the $\mathrm{Si}-\beta$ correlation in NGT as a whole was weak.

There are several limitations in this study. Validation of the current finding by direct measurement of $\mathrm{Si}$ and $\beta$ with intravenous glucose injection [33] is critically needed because use of [ISI $\mathrm{Iatsuda}]$ and $\left[\delta \mathrm{IRI}_{0-30} /\right.$ $\delta \mathrm{PG}_{0-30}$ ] for analysis of the hyperbolic law has not been performed. The correlation of the indices of Si and $\beta$ employed in this study, which were obtained by OGTT, with the actual values obtained by direct insulin clamp technique and intravenous glucose tolerance test, respectively, may not be very strong in the individuals with extraordinarily high $\mathrm{Si}$ and $\beta$. Ethnic diversity may play a role with Japanese subjects being leaner and more insulin sensitive $[5,15,19,38,39$ and current data] than subjects in Caucasian [6-8, 10-14, $17,18]$ at a comparable level of glucose regulation. In previous studies of non-diabetic subjects, the number of participants with a mean BMI similar to the value in $\mathrm{NGT}_{\mathrm{BMI} 1}$ in this study might have been too small to form a single group. At any rate, similar analyses in other ethnic groups are warranted. Also, analysis on the larger number of subjects is needed to definitively establish the current findings.

In conclusion, we found that the hyperbolic correlation between $\mathrm{Si}$ and $\beta$ is weaker in NGT than in NDH, and that it fades away in NGT subjects belonging to the lowest FPG or BMI tertile. The finding strongly suggests that a certain factor, such as Sg, may be a more dominant determinant of glucose metabolism rather than insulin secretion and action, and diminution of Sg might be the most proximal event in diabetes evolution.

\section{Acknowledgements}

We thank Drs. Kohei Iio, Shoichiro Nagasaka and Takuro Shimbo for constructive discussion, and Professor David Ruzicka for editorial assistance.

\section{Disclosures}

There is no conflict of interest that could be perceived as prejudicing the impartiality of the research reported.

\section{References}

1. Bergman RN, Phillips LS, Cobelli C (1981) Physiologic evaluation of factors controlling glucose tolerance in man: measurement of insulin sensitivity and beta-cell glucose sensitivity from the response to intravenous glucose. J Clin Invest 68: 1456-1467.
2. Kahn SE, Prigeon RL, McCulloch DK, Boyko EJ, Bergman RN, Schwartz MW, Neifing JL, Ward WK, Beard JC, Palmer JP, Porte D Jr (1993) Quantification of the relationship between insulin sensitivity and betacell function in human subjects. Evidence for a hyper- 
bolic function. Diabetes 42: 1663-1672.

3. Stumvoll M (2004) Control of glycaemia: from molecules to men. Minkowski Lecture 2003. Diabetologia 47: 770-781.

4. Ferrannini E, Mari A (2004) Beta cell function and its relation to insulin action in humans: a critical appraisal. Diabetologia 47: 943-956.

5. Sato Y, Komatsu M, Katakura M, Ohfusa H, Yamada S, Yamauchi K, Hiramatsu K, Ichikawa K, Aizawa T, Hashizume K (2002) Diminution of early insulin response to glucose in subjects with normal but minimally elevated fasting plasma glucose. Evidence for early beta-cell dysfunction. Diabet Med 19: 566-571.

6. Gastaldelli A, Ferrannini E, Miyazaki Y, Matsuda M, DeFronzo RA; San Antonio metabolism study (2004) Beta-cell dysfunction and glucose intolerance: results from the San Antonio metabolism (SAM) study. Diabetologia 47: 31-39.

7. Godsland IF, Jeffs JA, Johnston DG (2004) Loss of beta cell function as fasting glucose increases in the non-diabetic range. Diabetologia 47: 1157-1166.

8. Ferrannini E, Gastaldelli A, Miyazaki Y, Matsuda M, Mari A, DeFronzo RA (2005) Beta-Cell function in subjects spanning the range from normal glucose tolerance to overt diabetes: a new analysis. J Clin Endocrinol Metab 90: 493-500.

9. Bergman RN, Ader M, Huecking K, Van Citters G (2002) Accurate assessment of beta-cell function: the hyperbolic correction. Diabetes 51 Suppl 1: S212-220.

10. Festa A, Williams K, D'Agostino R Jr, Wagenknecht LE, Haffner SM (2006) The natural course of beta-cell function in nondiabetic and diabetic individuals: the Insulin Resistance Atherosclerosis Study. Diabetes 55: 1114-1120.

11. Mari A, Tura A, Pacini G, Kautzky-Willer A, Ferrannini E (2008) Relationships between insulin secretion after intravenous and oral glucose administration in subjects with glucose tolerance ranging from normal to overt diabetes. Diabet Med 25: 671-677.

12. Mari A, Tura A, Natali A, Laville M, Laakso M, Gabriel R, Beck-Nielsen H, Ferrannini E; RISC Investigators (2010) Impaired beta cell glucose sensitivity rather than inadequate compensation for insulin resistance is the dominant defect in glucose intolerance. Diabetologia 53: 749-756.

13. Retnakaran R, Hanley AJ, Raif N, Hirning CR, Connelly PW, Sermer M, Kahn SE, Zinman B (2005) Adiponectin and beta cell dysfunction in gestational diabetes: pathophysiological implications. Diabetologia 48: 9931001.

14. Utzschneider KM, Prigeon RL, Carr DB, Hull RL, Tong J, Shofer JB, Retzlaff BM, Knopp RH, Kahn SE (2006) Impact of differences in fasting glucose and glucose tolerance on the hyperbolic relationship between insulin sensitivity and insulin responses. Diabetes Care 29:
356-362.

15. Sakaue S, Ishimaru S, Ikeda D, Ohtsuka Y, Honda T, Suzuki J, Kawakami Y, Ishii J, Nishimura M (2007) Estimation of beta-cell function from the data of the oral glucose tolerance test. Am J Physiol Endocrinol Metab 292: E1575-1580.

16. Cobelli C, Toffolo GM, Dalla Man C, Campioni M, Denti P, Caumo A, Butler P, Rizza R (2007) Assessment of beta-cell function in humans, simultaneously with insulin sensitivity and hepatic extraction, from intravenous and oral glucose tests. Am J Physiol Endocrinol Metab 293: E1-E15.

17. Retnakaran R, Shen S, Hanley AJ, Vuksan V, Hamilton JK, Zinman B (2008) Hyperbolic relationship between insulin secretion and sensitivity on oral glucose tolerance test. Obesity 16: 1901-1907.

18. Utzschneider KM, Prigeon RL, Faulenbach MV, Tong J, Carr DB, Boyko EJ, Leonetti DL, McNeely MJ, Fujimoto WY, Kahn SE (2009) Oral disposition index predicts the development of future diabetes above and beyond fasting and 2-h glucose levels. Diabetes Care 32: 335-341.

19. Katakura M, Komatsu M, Sato Y, Hashizume K, Aizawa T (2004) Primacy of beta-cell dysfunction in the development of hyperglycemia: a study in the Japanese general population. Metabolism 53: 949-953.

20. Nauck MA, Sauerwald A, Ritzel R, Holst JJ, Schmiegel W (1998) Influence of glucagon-like peptide 1 on fasting glycaemia in type 2 diabetic patients treated with insulin after sulfonylurea secondary failure. Diabetes Care 21: 1925-1931.

21. Definition and diagnosis of diabetes mellitus and intermediate hyperglycemia: report of a WHO/IDF consultation. Available from http://whqlibdoc.who.int/ publications/2006/9241594934_eng.pdf..

22. Matsuda M, DeFronzo RA (1999) Insulin sensitivity indices obtained from oral glucose tolerance testing: comparison with the euglycemic insulin clamp. Diabetes Care 22: 1462-1470.

23. DeFronzo RA, Matsuda M (2010) Reduced time points to calculate the composite index. Diabetes Care 33: e93.

24. Kosaka K, Hagura R, Kuzuya T, Kuzuya N (1974) Insulin secretory response of diabetics during the period of improvement of glucose tolerance to normal range. Diabetologia 10: 775-782.

25. Stumvoll M, Mitrakou A, Pimenta W, Jenssen T, YkiJärvinen H, Van Haeften T, Renn W, Gerich J (2000) Use of the oral glucose tolerance test to assess insulin release and insulin sensitivity. Diabetes Care 23: 295301.

26. Kosaka K, Kuzuya T, Hagura R, Yoshinaga H (1996) Insulin response to oral glucose load is consistently decreased in established non-insulin-dependent diabetes mellitus: the usefulness of decreased early insulin 
response as a predictor of non-insulin-dependent diabetes mellitus. Diabet Med 13 (9 Suppl 6): S109-119.

27. Abdul-Ghani MA, Jenkinson CP, Richardson DK, Tripathy D, DeFronzo RA (2006) Insulin secretion and action in subjects with impaired fasting glucose and impaired glucose tolerance: results from the Veterans Administration Genetic Epidemiology Study. Diabetes 55: 1430-1435.

28. Sokal RR, Rohlf FJ (2011) Biometry $\left(4^{\text {th }}\right)$, WH Freeman and Company, New York.

29. Falster DS, Warton DI, Wright IJ. SMATR: standardised major axis tests and routines, ver 2.0. Available from http://www.bio.mq.edu.au/ecology/SMATR/.

30. Warton DI, Wright IJ, Falster DS, Westoby M (2006) Bivariate line-fitting methods for allometry. Biol Rev Camb Philos Soc 81: 259-291.

31. Holm S (1979) A simple sequentially rejective multiple test procedure. Scand J Statist 6: 65-70.

32. The Expert Committee on the Diagnosis and Classification of Diabetes Mellitus: Report of the expert committee on the diagnosis and classification of diabetes mellitus (1997) Diabetes Care 20: 1183-1197.

33. Bergman RN, Finegood DT, Ader M (1985) Assessment of insulin sensitivity in vivo. Endocr Rev 6: 45-86.

34. Lorenzo C, Wagenknecht LE, Rewers MJ, Karter AJ, Bergman RN, Hanley AJ, Haffner SM(2010) Disposition index, glucose effectiveness, and conversion to type 2 diabetes: the Insulin Resistance Atherosclerosis Study (IRAS). Diabetes Care 33: 2098-2103.

35. Holst JJ, Gromada J (2004) Role of incretin hormones in the regulation of insulin secretion in diabetic and nondiabetic humans. Am J Physiol Endocrinol Metab 287: E199-E206.

36. Meier JJ, Nauck MA (2010) Is the diminished incretin effect in type 2 diabetes just an epi-phenomenon of impaired beta-cell function? Diabetes 59: 1117-1125.

37. D'Alessio DA, Kahn SE, Leusner CR, Ensinck JW (1994) Glucagon-like peptide 1 enhances glucose tolerance both by stimulation of insulin release and by increasing insulin-independent glucose disposal. J Clin Invest 93: 2263-2266.

38. Taniguchi A, Nakai Y, Fukushima M, Kawamura H, Imura H, Nagata I, Tokuyama K (1992) Pathogenic factors responsible for glucose intolerance in patients with NIDDM. Diabetes 41: 1540-1546.

39. Taniguchi A, Nakai Y, Fukushima M, Imura $H$, Kawamura H, Nagata I, Florant GL, Tokuyama K (1994) Insulin sensitivity, insulin secretion, and glucose effectiveness in subjects with impaired glucose tolerance: a minimal model analysis. Metabolism 43: 714718 . 